\title{
ОТСТРАНЕНИЕ ОТ УЧАСТИЯ В ПУБЛИЧНЫХ ЗАКУПКАХ КАК СРЕДСТВО ПРОТИВОДЕЙСТВИЯ КОРРУПЦИИ ПО ПРАВУ ЕВРОПЕЙСКОГО СОЮЗА, ВЕЛИКОБРИТАНИИ, США И РОССИЙСКОЙ ФЕДЕРАЦИИ
}

\begin{abstract}
Аннотация: В статье проведен анализ института отстранения участников публичных закупок от участия в них за совершение коррупиионных правонарушений. Автором определяются понятие, правовая природа и виды отстранения участников публичных закупок по праву Европейского Союза, в законодательствах Великобритании, США и Российской Федераиии. Особое внимание уделяется сравнительному исследованию оснований и сроков отстранения в отечественном и зарубежном правопорядках. Рассматриваются вопросы отстранения участника публичной закупки за совершение коррупционных нарушений третьими лицами. При подготовке статьи автором использовались сравнительно-правовой, формально-юридический, а также системный и юридико-технический методы исследования. Определяются возможные пути развития исследуемого института в отечественном праве. В частности, отмечается необходимость расширения оснований для отстранения от участия в публичных закупках за совершение коррупционных правонарушений. В информационных целях иелесообразно обеспечить ведение реестра участников публичных закупок, отстраненных от участия 6 них вследствие совершения коррупиионных и иных правонарушений.
\end{abstract}

Ключевые слова: Государственные закупки, публичные закупки, государственный контракт, заключение договоров, контрактная система, отстранение участников закупки, государственные нужды, государственный заказ, коррупция, противодействие коррупции.

Abstract: This article presents the analysis of the institution of excluding parties from participating in public procurement due to corruption violations. The author defines the notion, legal nature, and types of exclusion of parties from public procurement according to the law of the European Union, Great Britain, United States, and Russian Federation. A special attention is given to the comparative analysis of the basis and terms of exclusion within Russian and foreign legislations, including removal from participation for third-party corruption violations. The author determines possible ways to improve this institution within Russian legislation, and notes the need to broaden the bases for exclusion from participation due to corruption violations. For information purposes it is reasonable to create and maintain a registry of participants of public procurement that have previously been excluded due to corruption or other violations.

Keywords: State needs, exclusion of suppliers, contract system, contracting, government contract, public procurement, government procurement, state order, corruption, fighting corruption.

ак правильно отмечают современные российские специалисты, эффективное управление процессом противодействия коррупции в системе государственных и муниципальных закупок может стать для Российской Федерации существенным фактором снижения трансакционных издержек и экономии бюджетных средств [8, с. 3].

В Федеральном законе от 5 апреля 2013 г. № 44-Ф3 «О контрактной системе в сфере закупок товаров, работ, услуг для обеспечения государственных и муниципальных нужд» (далее - Закон о контрактной системе) [3] предусмотрены правовые средства, направленные на противодействие коррупции в сфере закупок това- ров, работ, услуг для обеспечения государственных и муниципальных нужд (далее - публичные закупки). Однако, на наш взгляд, потенциал далеко не всех из них использован отечественным законодателем в полной мере. Одним из таких средств является отстранение участника публичной закупки от участия в ней, под которым мы понимаем отстранение участника закупки от участия в определении поставщика (подрядчика, исполнителя) и отказ от заключения контракта с победителем определения поставщика (подрядчика, исполнителя) (ч. 9 ст. 31 Закона о контрактной системе).

Обратимся к сравнительному анализу российского и зарубежного законодательства, а также права 
DOI: $10.7256 / 1811-9018.2015 .8 .15831$

При цитировании этой статьи сноска на доі обязательна

\section{Право и политика 8 (188) • 2015}

Европейского Союза (далее - ЕС), в целях определения путей совершенствования отечественного института отстранения участника публичной закупки от участия в ней за совершение коррупционных правонарушений.

Положения отечественного законодательства об отстранении участников публичных закупок за совершение коррупцинных правонарушений. Основанием для отстранения от участия в публичной закупке является несоответствие ее участника требованиям, указанным в ч.ч. 1, 1.1 и 2 ст. 31 Закона о контрактной системе, либо предоставление им недостоверной информации в отношении своего соответствия этим требованиям. Согласно п. 7 ч. 1 ст. 31 Закона о контрактной системе к требованиям, предъявляемым ко всем участникам закупки, относится отсутствие у участника закупки - физического лица либо у руководителя, членов коллегиального исполнительного органа или главного бухгалтера участника закупки юридического лица судимости за преступления в сфере экономики (разд. VIII Уголовного кодекса Российской Федерации (далее - УК РФ) [7]. Данное законоположение недостаточно логично. Оно не способствует достижению такой заявленной законодателем цели правового регулирования общественных отношений, складывающихся в сфере публичных закупок, как предотвращение коррупции (ч. 1 ст. 1 Закона о контрактной системе). Ведь при наличии у вышеперечисленных лиц судимости за коррупционные преступления в публичном секторе (например, дача взятки (ст. 291 УК РФ) и посредничество во взяточничестве (ст. $291^{1}$ УК РФ). - Прим. авт.) участник публичной закупки не может быть отстранен от участия в ней. В соответствии с УК РФ данные преступления относятся к преступлениям против государственной власти, а не к преступлениям в сфере экономики. В тоже время наличие судимости у тех же самых лиц за коррупционное преступление в частном секторе, предусмотренное ст. 204 УК РФ «Коммерческий подкуп», является основанием для отстранения участника публичной закупки.

Понятие и виды отстранения правонарушителей от участия в публичных закупках в праве ЕС и в законодательствах Великобритании и США. В законодательствах государств с развитым правопорядком, таких как США и Великобритания, а также в праве ЕС, привлечение участника публичной закупки или связанных с ним лиц (например, его должностных лиц) к ответственности за совершение любых коррупционных правонарушений является основанием для отстранения от участия в закупке.

За рубежом используются различные термины для обозначения мер по отстранению хозяйствующих субъектов от участия в публичных закупках. Так, в праве Европейского Союза и в законодательстве Великобритании применяется термин «исключение из состава участников закупки» (exclusion) [12; 20], в США - «временное отстранение от участия в закупках» (debarment, suspension). Ввиду тождественной природы мер, обозначаемых с помощью данных терминов, В. - Е. Соуп вводит в научный оборот обобщающую категорию - «дисквалификация» (disqualification) $[18$, p. 31]. Входящие в ее объем меры являются, по мнению С. Скунера и ряда других специалистов, административно-правовыми средствами защиты государственных интересов (administrative remedies), вводящими ограничения на заключение государственных контрактов с хозяйствующими субъектами - нарушителями правовых норм и норм профессиональной этики, а при наличии заключенного государственного контракта - на увеличение срока его действия и объема поставок [17, pp. 211, 212 - 213; 19, р. 50].

Как в праве ЕС, так и в законодательствах Великобритании и США, отстранение хозяйствующих субъектов от участия в публичных закупках носит временный характер. Основанием отстранения является совершение не только коррупционных, но и широкого круга иных правонарушений.

Отстранение от участия в публичных закупках может быть обязательным и дискреционным.

Обязательное отстранение участника публичной закупки осуществляется дисквалифицирующим субъектом в обязательном порядке. Применение этой меры составляет обязанность дисквалифицирующего субъекта и не зависит от его усмотрения. В то же время в ряде случаев он может наделяться полномочиями по юридической квалификации деяния как правонарушения, влекущего за собой отстранение, определению продолжительности отстранения и круга лиц, подлежащих отстранению.

Основанием обязательного отстранения, как правило, является совершение хозяйствующим субъектом и связанными с ним лицами серьезных правонарушений.

Дискреционное отстранение - это мера, применение которой в отношении участника закупки зависит от усмотрения дисквалифицирующего субъекта.

Правовая природа отстранения участников публичной закупки за совершение коррупционных правонарушений. Совершение лицом коррупционного правонарушения может явиться основанием поражения его в правах участника публичной закупки. Например, по Закону о контрактной системе ограничение прав коррупционера - физического лица всегда сопряжено 
с назначением ему уголовного наказания. К такому выводу позволяет прийти системный анализ положений п. 7 ч. 1 и ч. 9 ст. 31 названного Закона. Согласно ним отстранение участника закупки от участия в определении поставщика (подрядчика, исполнителя) или отказ от заключения контракта с победителем определения поставщика (подрядчика, исполнителя) осуществляется только в случае наличия у него судимости за преступления в сфере экономики. В свою очередь, возникновение состояния судимости связано со вступлением в законную силу не просто обвинительного приговора, а приговора с назначением наказания (ч. 2 ст. 86 УК РФ).

Не является ли установление в отношении физического лица в связи с его уголовным осуждением дополнительных правовых последствий в сфере публичных закупок нарушением принципа «ne bis in idem»? В постановлении от 21 ноября 2002 г. № 15-П Конституционный Суд Российской Федерации подчеркнул недопустимость связывания с уголовным осуждением таких правовых последствий, которые по своей сути являются дополнительной карой и при этом выходят за рамки наказания, определенные УК РФ [5].

Определяя правовую природу ограничения прав коррупционера - физического лица сошлемся на правовую позицию Конституционного Суда Российской Федерации, сформулированную в одном из его определений относительно ограничения прав физического лица вследствие наличия у него судимости. По мнению высшей судебной инстанции, запрет на заключение трудовых договоров с лицами, имеющими неснятую или непогашенную судимость за умышленные тяжкие и особо тяжкие преступления, направлен на защиту общественных интересов и прав отдельных групп граждан. Конституционный Суд Российской Федерации прямо подчеркнул, что данный запрет не является дополнительным наказанием за преступление [4]. Следовательно, указанное ограничение представляет собой специальную меру защиты публичных интересов.

Руководствуясь логикой Конституционного Суда Российской Федерации, представляется возможным признать отстранение участника публичной закупки от участия в ней за совершение коррупционного преступления в качестве специальной защитной меры публичных интересов.

Аналогичным образом квалифицируют отстранение от участия в публичных закупках и зарубежные специалисты. По мнению В. - Е. Соуп, отстранение хозяйствующих субъектов от участия в государственных закупках за совершение коррупционных правонарушений является не видом наказания, а представляет собой меру по предупреждению хищения бюджетных средств в результате коррупционных действий [18, p. 46].

В США отстранение от участия в государственных закупках также не рассматривается как наказание. В Федеральных закупочных правилах США [13] прямо указывается на необходимость отстранения от участия в закупках «исключительно в публичных интересах для защиты правительства» с целью обеспечения исполнения законодательных требований о заключении государственных контрактов только c «ответственными» партнерами (FAR 9.402(a), (b). По законодательству США отстранение от участия в государственных закупках может быть только дискреционным. Это является еще одним препятствием признания его дополнительным наказанием за совершенное правонарушение (FAR 9.406-1(a).

Американские правоведы отмечают, что рассматриваемая мера защиты интересов правительства США не направлена на наказание участников закупки [19, p. 50]. Аналогичной позиции придерживаются и американские суды. Они отрицают возможность квалификации отстранения от участия в государственных закупках в качестве вида наказания [11; 22].

Именно защитный, а не карательный характер отстранения от участия в государственных закупках, позволяет объяснять применение данной меры в США только «на будущее время» - перспективно, а не немедленно, в отношении уже заключенных государственных контрактов (FAR 9.405-1).

Основания и сроки отстранения участников публичной закупки за совершение коррупционных правонарушений. Как уже отмечалось выше, по отечественному законодательству основанием для отстранения участника публичной закупки от участия в ней является наличие у него или у связанных с ним лиц судимости только за те коррупционные преступления, которые отнесены к преступлениям в сфере экономики (п. 7 ч. 1 ст. 31 Закона о контрактной системе). Наличие судимости за дачу взятки или посредничество во взяточничестве не является основанием для отстранения, так как указанные коррупционные преступления относятся к преступлениям против государственной власти (разд. Х УК РФ). Не влечет отстранения участника публичной закупки от участия в ней и привлечение его к административной ответственности за совершение коррупционного правонарушения, предусмотренного ст. 19.28 Кодекса Российской Федерации об административных правонарушениях (далее - КоАП РФ) [2].

В соответствии с п. 7 ч. 1 ст. 31 Закона о контрактной системе основания отстранения участника 
DOI: $10.7256 / 1811-9018.2015 .8 .15831$

При цитировании этой статьи сноска на доі обязательна

\section{Право и политика 8 (188) • 2015}

публичной закупки от участия в ней за совершение коррупционного правонарушения отпадают в момент погашения или снятия судимости. Из этого следует, что в отечественном законодательстве срок отстранения участника публичной закупки от участия в ней может быть различным, так как, например, момент погашения судимости зависит от ряда факторов: является ли назначенное наказание реальным или условным, назначены ли наказание в виде лишения свободы или более мягкий вид наказания. При отбывании лишения свободы сроки погашения судимости дифференцируются в зависимости от категории совершенного преступления (ч. 3 ст. 86 УК РФ).

Как в праве ЕС, так и в законодательствах Великобритании и США, совершение коррупционных нарушений является основанием для отстранения хозяйствующего субъекта от участия в публичных закупках. При чем коррупционные акты могут выражаться в нарушении не только правовых норм, но и норм профессиональной этики. Являясь основанием для отстранения хозяйствующего субъекта от участия в публичных закупках, эти нарушения не должны быть обязательно сопряжены с участием в таких закупках, а могут совершаться и в иных сферах общественных отношений. Стоит заметить, что такой подход, применяемый и в странах - участницах ЕС, и в США, критикуется отдельными иностранными специалистами [23, pp. $255-256]$.

Согласно п. «b» парагр. 1 ст. 57 Директивы 2014/24/ EU о публичных закупках (так называемой «классической» директиве) (далее - Директива 2014/24/EU) [12], являющейся базовой в сфере публичных закупок на территории ЕС, основанием для обязательного отстранения хозяйствующего субъекта от участия в публичной закупке является вступление в законную силу судебного приговора о привлечении его к уголовной ответственности за коррупцию. Понятие «коррупция» раскрывается в ст. 3 Акта Совета ЕС от 26 мая 1997 г. и ст. 3 (1) Общей акции Совета ЕС 98/742/ПВД. В Директиве 2014/24/EU отдельно оговаривается, что основанием обязательного отстранения хозяйствующего субъекта - юридического лица является привлечение его должностных лиц к уголовной ответственности за совершение коррупционных преступлений. К должностным лицам юридического лица отнесены члены его административного, управленческого, контролирующего органов или лица, наделенные полномочиями по представлению интересов юридического лица, принятию решений, осуществлению контроля в отношении него.
Стоит отметить, что даже при наличии оснований для обязательного отстранения заказчики вправе допустить хозяйствующих субъектов к участию в закупке, если этого требуют публичные интересы (парагр. 1 ст. 57 Директивы 2014/24/EU).

В качестве оснований для дискреционного отстранения в Директиве 2014/24/EU выделены:

1) виновное ненадлежащее исполнение хозяйствующим субъектом своих профессиональных функций, ставящее под сомнение его добросовестность, и наличие у заказчика любых сведений, подтверждающих данный факт (п. «с» парагр. 4 ст. 57 Директивы 2014/24/EU);

2) наличие у заказчика достоверных сведений о заключении хозяйствующими субъектами соглашения, ограничивающего конкуренцию между участниками закупки (п. «d» парагр. 4 ст. 57 Директивы 2014/24/EU);

3) конфликт интересов, если он не может быть устранен иными средствами, в меньшей степени ограничивающими право хозяйствующего субъекта участвовать в закупке (п. «е» парагр. 4 ст. 57 Директивы 2014/24/EU).

Категория «ненадлежащее исполнение профессиональных функций», упомянутая в п. 1 вышеприведенного перечня и использованная в формулировке п. «с» ч. 4 ст. 57 Директивы 2014/24/EU, охватывает большое количество правонарушений, в том числе коррупционной направленности, совершенных при осуществлении профессиональной или предпринимательской деятельности [16, pp. 267, 272; 18, p. 83].

Заметим, что хозяйствующий субъект вправе предоставить доказательства своей надежности. В случае достаточности таких доказательств заказчик может допустить хозяйствующего субъекта к участию в публичной закупке, даже если имеются основания для обязательного или дискреционного отстранения (парагр. 6 ст. 57 Директивы 2014/24/EU).

В законодательстве Великобритании [20], являющейся членом ЕС, воспроизведены положения Директивы 2014/24/EU. Определенной спецификой, позволяющей учесть особенности национального правопорядка, обладают лишь основания для обязательного отстранения хозяйствующего субъекта от участия в публичных закупках. Участник закупки подлежит отстранению за совершение целого ряда коррупционных преступлений, предусмотренных Актом о коррупции в органах власти 1889 г. и Актом о предотвращении коррупции 1906 г. Отдельно выделены такие основания как дача взятки по общему праву (the common law offence of bribery) и дача взятки в понимании Акта о народном представительстве 
1983 г. или Акта о взяточничестве 2010 г. [20, reg. 57]. Особенностью Акта 2010 г. является то, что в нем дача взятки рассматривается в качестве уголовного деяния, совершаемого юридическим лицом [6, с. $82-83]$.

Согласно парагр. 7 ст. 57 Директивы 2014/24/EU максимальный срок обязательного отстранения в странах - членах ЕC, по общему правилу, не должен превышать пяти лет со дня вступления приговора в законную силу, а дискреционной - трех лет с момента совершения соответствующего действия или наступления события. Например, в законодательстве Великобритании закреплены максимально возможные сроки обязательного и дискреционного отстранения - пять лет и три года соответственно [20, reg. 57].

Срок отстранения хозяйствующего субъекта от участия в федеральных закупках по законодательству США зависит от применяемого вида отстранения. Максимальная продолжительность краткосрочного отстранения (suspension) составляет двенадцать месяцев (FAR 9.407-4). Помощник Генерального прокурора CША вправе потребовать увеличения этого срока до восемнадцати месяцев (FAR 9.407-4). Продолжительность же долговременного отстранения (debarment) не должна превышать, по общему правилу, трех лет (FAR 9.406-4).

Основанием для применения обоих видов отстранения является совершение хозяйствующим субъектом правонарушений и нарушений норм профессиональной этики (FAR 9.406-2; 9.407-2). Такое основание для отстранения как совершение правонарушений, связанных с участием в закупочной процедуре и исполнением государственного контракта, выделено в Федеральных закупочных правилах США отдельно (FAR 9.406-2(a)(1); 9.407-2(a)(1).

Как уже отмечалось выше, Федеральными закупочными правилами США не предусматривается обязательное отстранение хозяйствующего субъекта. Решение об отстранении хозяйствующего субъекта от участия в федеральных закупках всегда принимается дисквалифицирующим субъектом (в этом качестве выступает глава федерального органа исполнительной власти или назначенное им должностное лицо (FAR 9.403). - Прим. авт.) по своему усмотрению.

Обстоятельства, послужившие основанием для долговременного отстранения, должны быть установлены вступившим в законную силу решением суда (FAR 9.406-2(a). Для краткосрочного отстранения не требуется установления соответствующих оснований судебным решением, достаточно лишь наличия у дисквалифицирующего субъекта надлежащих доказательств (adequate evidence) (FAR 9.407-2(a). Последние определяются как сведения, достаточные для обосно- ванного предположения о совершении лицом определенного противоправного действия или бездействия (FAR 2.101). Признаками надлежащих доказательств являются их относимость и достоверность (FAR 9.4071(b), а о наличии таких доказательств свидетельствует составляемый дисквалифицирующим субъектом обвинительный акт (indictment) (FAR 9.407-2(b).

B США решение об отстранении хозяйствующего субъекта от участия в федеральных закупках обязательно для всех федеральных заказчиков вне зависимости от того, кто его вынес (FAR 9.407-1(d); FAR 9.406-1(c). В целях информирования заказчиков о принятом решении об отстранении хозяйствующего субъекта от участия в федеральных закупках Администрация общих услуг (General Services Administration) ведет общедоступный специальный реестр отстраненных поставщиков (system for award management exclusions) (FAR 9.404).

В ЕС и Великобритании субъектные пределы действия решения об отстранении четко не определены [18, p. 152].

Отстранение участника публичной закупки от участия в ней за совершение коррупционных нарушений третьими лицами. Участник публичной закупки может быть отстранен от участия в ней не только за собственные правонарушения, но и вследствие совершения правонарушения связанными с ним третьими лицами. Это позволяет исключить случаи участия в публичных закупках уже отстраненного правонарушителя через входящих с ним в одну группу лиц участников, а также привлечения его к исполнению контракта в качестве субподрядчика (соисполнителя) [9, p. 172]. Кроме того, отстранение хозяйствующего субъекта от участия в публичных закупках за коррупционные нарушения, совершенные третьими лицами, имеет смысл в случаях, когда в правовой системе государства не допускается привлечение юридических лиц к уголовной ответственности. Юридические лица могут быть отстранены от участия в публичных закупках за преступления, совершенные их должностными лицами [14, p. 279]. Так, согласно п. 7 ч. 1 и ч. 9 ст. 31 Закона о контрактной системе участник закупки - юридическое лицо подлежит отстранению от участия в публичной закупке при наличии судимости за преступления в сфере экономики у его руководителя, членов коллегиального исполнительного органа или главного бухгалтера.

В зарубежной юридической литературе [18, p. 170] выделяется несколько категорий третьих лиц, чьи коррупционные правонарушения могут повлечь отстранение хозяйствующего субъекта от участия в публичных закупках. 
DOI: $10.7256 / 1811-9018.2015 .8 .15831$

При цитировании этой статьи сноска на доі обязательна

\section{Право и политика $8(188) \cdot 2015$}

К первой группе отнесены физические лица.

Совершение физическими лицами коррупционных правонарушений может явиться основанием для отстранения юридического лица от участия в публичных закупках. Например, в США организация подлежит отстранению, если ее должностное лицо, директор, участник, партнер, работник или другое связанное с ней физическое лицо (например, агент) совершили коррупционное правонарушение при исполнении своих обязанностей перед этой организацией, а последняя знала о противоправном деянии, одобряла его или попустительствовала ему (FAR 9.406-5(a).

Круг физических лиц, за преступления которых юридическое лицо подлежит отстранению от участия в публичных закупках, зависит от того, какой подход положен в основу признаваемой в зарубежных правопорядках доктрины корпоративной ответственности (corporate liability): доктрина субститутивной ответственности (vicarious liability) или доктрина идентификации (doctrine of identification) [1]. Если главенствующей является доктрина субститутивной ответственности, то юридическое лицо отстраняется от участия в публичных закупках за противоправные действия любых своих работников. Доктрина же идентификации ограничивает круг физических лиц, за правонарушения которых организация может отстраняться, должностными лицами, формирующими и изъявляющими ее волю.

Ко второй группе третьих лиц, за чьи коррупционные правонарушения хозяйствующий субъект может быть отстранен от участия в публичных закупках, отнесены взаимосвязанные организации (connected companies): материнская, дочерние и сестринские компании.

Так, согласно Федеральным закупочным правилам CШA (FAR 9.406-1(b), 9.407-1(c) допускается отстранение от участия в федеральных государственных закупках не только организации - правонарушителя, но и всех аффилированных с ней лиц (affiliates), к которым, исходя из нормативного определения этого понятия, относятся материнская, дочерние, сестринские компании (FAR 9.403).

В Великобритании, напротив, материнская и дочерняя компании не подлежат отстранению от участия в публичных закупках за правонарушения друг друга. Данный запрет не закреплен на нормативном уровне, однако следует из разъяснений Управления государственной торговли Великобритании (Office of Government Commerce) [15, para 3.2].

Следующую группу лиц, чьи коррупционные правонарушения могут повлечь отстранение хо- зяйствующего субъекта от участия в публичных закупках, образуют сотрудничающие компании (cooperating companies). К ним относятся, например, субподрядчики (соисполнители) поставщика по государственному контракту.

По праву ЕС (абз. 2 парагр. 1 ст. 63 Директивы 2014/24/EU), если планируемые хозяйствующим субъектом к привлечению субподрядчики (соисполнители) были отстранены и у него отсутствуют собственные средства и персонал для надлежащего исполнения государственного контракта, то он тоже подлежит отстранению от участия в закупке [10, р. 319]. В целях выявления наличия указанных оснований для отстранения заказчик вправе потребовать от участников публичной закупки информацию о планируемых ими к привлечению субподрядчиках (соисполнителях).

В Великобритании заказчик также вправе потребовать от участников публичной закупки предоставления ему сведений о лицах, планируемых ими к привлечению в качестве субподрядчиков (соисполнителей). В случае совершения последними правонарушений заказчик имеет право отказать в согласовании их кандидатур. Если в результате этого участник публичной закупки утрачивает возможность осуществить поставку товара (выполнить работу, оказать услугу), то он может быть отстранен от участия в закупке [18, p. 198].

В 2010 г. в США были внесены изменения в ст. 2455(c)(1) Закона об оптимизации федеральных закупок 1994 г., согласно которым допускается установление запрета на привлечение отстраненных от участия в федеральных закупках лиц в качестве субподрядчиков (соисполнителей) любого уровня кооперации при закупке коммерчески недоступной продукции. Если ли же поставщик по государственному контракту закупает коммерчески доступную продукцию (commercially available off-the-shelf items), то возможно установление запрета на привлечение дисквалифицированных лиц в качестве субподрядчиков (соисполнителей) первого уровня кооперации. Указанные законодательные изменения отразились на содержании Федеральных закупочных правил США. В соответствии с ними привлечение отстраненных от участия в федеральных закупках лиц в качестве субподрядчиков (соисполнителей) допускается лишь с согласия заказчика, одобренного руководителем его ведомства (FAR 9.405-2(a). При включении в государственный контракт специальной оговорки поставщик не вправе закупать у субподрядчиков (соисполнителей) коммерчески недоступную продукцию на сумму свыше 30 тыс. долл. В исключительных случаях такая закупка все же разрешается, но при условии предварительного 
письменного уведомления об этом заказчика. В нем поставщик (подрядчик, исполнитель) должен обосновать необходимость осуществления закупки и указать предпринятые им меры по защите интересов заказчика (FAR 9.405-2(b); 52.209-6).

Перспективы развития в отечественном праве института отстранения от участия в публичных закупках за совершение коррупционных правонарушений. Проведенное исследование позволяет не только определить сходства и различия подходов, используемых в российском и зарубежном правопорядках, но и наметить перспективы развития отечественного института отстранения от участия в публичных закупках за совершение коррупционных правонарушений.

Во-первых, считаем целесообразным расширить предусмотренный Законом о контрактной системе перечень оснований для отстранения участников публичных закупок от участия в них. Следует включить в этот перечень такие основания, как вынесение обвинительного приговора за совершение коррупционного преступления и постановления о назначении административного наказания за совершение коррупционного правонарушения. Ввиду отсутствия единого подхода к пониманию понятий «коррупционное преступление» и «коррупционное правонарушение» нужно указать в Законе о контрактной системе ссылки на статьи УК РФ и КоАП РФ, закрепляющие составы коррупционных правонарушений.

Во-вторых, реализация первого предложения потребует установления сроков давности, за преде- лами которых участник публичной закупки - правонарушитель не может быть отстранен от участия в ней. Моментом начала течения этого срока должно являться вступление в законную силу обвинительного приговора или постановления о назначении административного наказания.

В-третьих, в информационных целях целесообразно обеспечить ведение реестра участников публичных закупок, отстраненных от участия в них вследствие совершения коррупционных и иных правонарушений. Это позволит заказчикам осуществлять оперативную проверку соблюдения участниками закупок предъявляемых к ним требований. Предусмотренный Законом о контрактной системе (ст. 104) реестр недобросовестных поставщиков не позволяет решить данную задачу.

В-четвертых, отстранение участника публичной закупки, совершившего коррупционное правонарушение, от участия в ней должно быть обязательным, то есть не зависящим от усмотрения заказчика. Вместе с тем считаем необходимым наделить заказчика правом заключать государственный (муниципальный) контракт с таким участником, если этого требует публичный интерес.

В-пятых, с целью повышения эффективности мер по противодействию коррупции необходимо рассмотреть вопрос о расширении круга лиц, совершение коррупционных правонарушений которыми является основанием для отстранения от участия в публичной закупке связанных с такими лицами хозяйствующих субъектов.

\section{Библиография:}

1. Антонова, Е.Ю. Современные концепции корпоративной (коллективной) уголовной ответственности [Текст] / Е.Ю. Антонова // Современное право. - 2011. - № 6. - С. 135 - 140.

2. Кодекс Российской Федерации об административных правонарушениях от 30 дек. 2001 г. № 195-Ф3 // Собр. законодательства Рос. Федерации. - 2002. - № 1 (часть 1), ст. 1; 2008. - № 52 (часть 1), ст. 6235.

3. О контрактной системе в сфере закупок товаров, работ, услуг для обеспечения государственных и муниципальных нужд: фед. закон от 5 апр. 2013 г. № 44-Ф3 // Собр. законодательства Рос. Федерации. - 2013. - № 14, ст. 1652.

4. Об отказе в принятии к рассмотрению жалобы гражданина Лазарева Сергея Федоровича на нарушение его конституционных прав положением части второй статьи 331 Трудового кодекса Российской Федерации: определение Конституционного Суда Рос. Федерации от 26 янв. 2010 г. № 127-О-О. [Электронный ресурс]. Документ официально опубликован не был. Доступ из справ. - правов. системы «КонсультантПлюс».

5. По делу о проверке конституционности положений подпункта 1 пункта 3 и абзаца первого пункта 6 статьи 9 Закона Российской Федерации «О вынужденных переселенцах» в связи с жалобой гражданина М.А. Мкртычана : постановление Конституционного Суда Рос. Федерации от 21 нояб. 2002 г. № 15-П // Собр. законодательства Рос. Федерации. - 2002. - № 48, ст. 4829.

6. Роль предпринимательских структур в противодействии коррупции [Текст]: науч. -практ. пособ. / отв. ред. Н.Г. Семилютина, Е.И. Спектор. - М.: ИЗиСП, Контракт, 2012. - 240 с.

7. Уголовный кодекс Рос. Федерации от 13 июня 1996 г. № 63-Ф3 // Собр. законодательства Рос. Федерации. - 1996. - № 25, ст. 2954.

8. Храмкин, А.А. Противодействие коррупции в госзакупках [Текст]: моногр. / А.А. Храмкин. - М.: Юриспруденция, 2011. - 152 c. 
DOI: $10.7256 / 1811-9018.2015 .8 .15831$

При цитировании этой статьи сноска на dоі обязательна

\section{Право и политика 8 (188) 2015}

9. Anechiarico, F., Jacobs, J. Purging Corruption from Public Contracting: The Solutions are Now Part of the Problem // New York Law School Law Review. - 1995. - Vol. 40. - pp. 143 - 175.

10. Arrowsmith, S. The Law of Public and Utilities Procurement. - London: Sweet \& Maxwell, 2005. - cxxxviii + 1547 p.

11. Bae v. Shalala, 44 F3d 489 (7th Cir 1995).

12. Directive 2014/24/EU of the European Parliament and of the Council of 26 February 2014 on public procurement and repealing Directive 2004/18/EC // Official Journal of the European Union. - 2014. - L 94/65.

13. Federal Acquisition Regulation [Электронный ресурс]. - Режим доступа: URL: https://www.acquisition.gov/?q=browsefar (дата обращения: 15.05.2015).

14. Hamdani, A., Klement, A. Corporate Crime and Deterrence // Stanford Law Review. - 2008. - Vol. 61. - № 2. - pp. 271 - 310.

15. Mandatory Exclusion: Office of Government Commerce Guidance on the Mandatory Exclusion of Economic Operators in the New Procurement Regulations. [Электронный ресурс]. - Режим доступа: URL: http://webarchive.nationalarchives.gov. uk/20110601212617/http:/www.ogc.gov.uk/documents/Mandatory_Exclusion_Guidance_-_February_2010_Update_on_new_ template_(2).pdf (дата обращения: 15.05.2015).

16. Piselli, E. The Scope for Excluding Providers Who Have Committed Criminal Offences under the EU Procurement Directives // Public Procurement Law Review. - 2000. - Vol. 6. - pp. 267 - 286.

17. Schooner, S. The Paper Tiger Stirs: Rethinking Exclusion and Debar-ment // Public Procurement Law Review. - 2004. - Vol. 13. - № 5. - pp. $211-217$.

18. Sope, W. - El. Fighting Corruption in Public Procurement: A Comparative Analysis of Disqualification or Debarment Measures. - Oxford-Portland: Hart Publishing, 2012. - xlix + 306 p.

19. Tillipman, J. A House of Cards Falls: Why "Too Big to Debar" is All Slogan and Little Substance // Fordham Law Review Res Gestae. - 2012. - Vol. 80. - Paper 7. - pp. 49 - 58.

20. The Public Contracts Regulations 2015 (Regulation 57). [Электронный ресурc]. - Режим доступа: URL: http://www.legislation. gov.uk/uksi/2015/102/regulation/57/made (дата обращения: 15.05.2015).

21. Trepte, P. Regulating Procurement: Understanding the Ends and Means of Public Procurement Regulation. - Oxford: Oxford University Press, 2004. -432 p.

22. United States v. Bizzell, 921 F2d 263 (10th Cir 1990).

23. Yukins, C. Suspension and Debarment: Re-examing the Process // Public Procurement Law Review. - 2004. - Vol. 13. - № 5. pp. $255-259$

\section{References (transliterated):}

1. Antonova, E.Yu. Sovremennye kontseptsii korporativnoi (kollektivnoi) ugolovnoi otvetstvennosti [Tekst] / E.Yu. Antonova // Sovremennoe pravo. - 2011. - № 6. - S. 135 - 140.

2. Khramkin, A.A. Protivodeistvie korruptsii v goszakupkakh [Tekst] : monogr. / A.A. Khramkin. - M. : Yurisprudentsiya, 2011. $-152 \mathrm{~s}$.

3. Anechiarico, F., Jacobs, J. Purging Corruption from Public Contracting : The Solutions are Now Part of the Problem // New York Law School Law Review. - 1995. - Vol. 40. - pp. 143 - 175.

4. Arrowsmith, S. The Law of Public and Utilities Procurement. - London : Sweet \& Maxwell, 2005. - cxxxviii + 1547 p.

5. Bae v. Shalala, 44 F3d 489 (7th Cir 1995).

6. Hamdani, A., Klement, A. Corporate Crime and Deterrence // Stanford Law Review. - 2008. - Vol. 61. - № 2. - pp. 271 - 310.

7. Piselli, E. The Scope for Excluding Providers Who Have Committed Criminal Offences under the EU Procurement Directives // Public Procurement Law Review. - 2000. - Vol. 6. - pp. 267 - 286.

8. Schooner, S. The Paper Tiger Stirs: Rethinking Exclusion and Debar-ment // Public Procurement Law Review. - 2004. - Vol. 13. - № 5. - pp. $211-217$.

9. Sope, W. - El. Fighting Corruption in Public Procurement: A Comparative Analysis of Disqualification or Debarment Measures. - Oxford-Portland: Hart Publishing, 2012. - xlix + 306 p.

10. Tillipman, J. A House of Cards Falls: Why "Too Big to Debar" is All Slogan and Little Substance // Fordham Law Review Res Gestae. - 2012. - Vol. 80. - Paper 7. - pp. 49 - 58.

11. Trepte, P. Regulating Procurement: Understanding the Ends and Means of Public Procurement Regulation. - Oxford: Oxford University Press, 2004. - 432 p.

12. Yukins, C. Suspension and Debarment: Re-examing the Process // Public Procurement Law Review. - 2004. - Vol. 13. - № 5. pp. $255-259$ 